\title{
NASA's Involvement in Technology Development and Transfer: The Ohio Hybrid Bus Project
}

Larry A. Viterna

Lewis Research Center

Cleveland, Ohio

Prepared for the

Electrical Insulation Conference/Electrical Manufacturing and Coil Winding Expo '97 cosponsored by IEEE, NEMA, and EMCWA

Chicago, Illinois, September 22-25, 1997

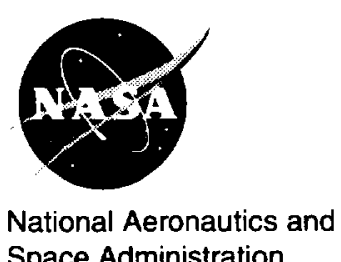

Space Administration 
Trade names or manufacturers' names are used in this report for identification only. This usage does not constitute an official endorsement, either expressed or implied, by the National Aeronautics and Space Administration. 


\title{
NASA'S INVOLVEMENT IN TECHNOLOGY DEVELOPMENT AND TRANSFER: THE OHIO HYBRID BUS PROJECT
}

\author{
Larry A. Viterna, Ph.D. \\ NASA Lewis Research Center
}

\begin{abstract}
A government and industry cooperative is using advanced power technology in a city transit bus that will offer double the fuel economy, and reduce emissions to one tenth of government standards. The heart of the vehicle's power system is a natural gas fueled generator unit. Power from both the generator and an advanced energy storage system is provided to a variable speed electric motor attached to the rear drive axle. A unique aspect of the vehicle's design is its use of "super" capacitors for recovery of energy during braking. This is the largest vehicle ever built using this advanced energy recovery technology. This paper describes the project goals and approach, results of its system performance modeling, and the status of the development team's effort.
\end{abstract}

Keywords: Hybrid Electric Vehicle

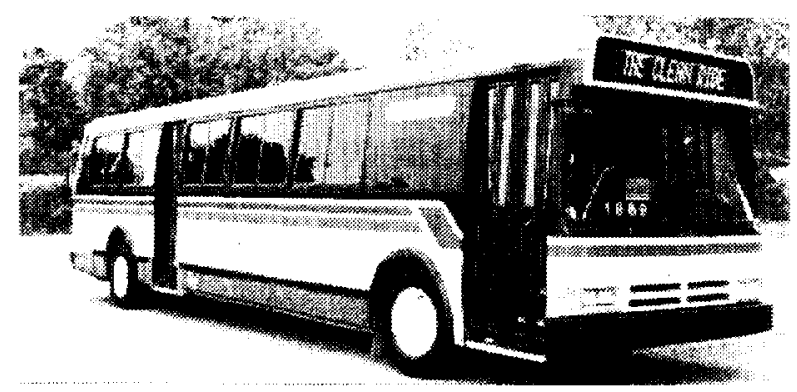

I. INTRODUCTION

New environmental emission standards are a challenge and an opportunity for industry and governments who manufacture and operate urban transit vehicles. In addition, reduced federal support for regional transit authorities has heightened the need for buses with increased fuel economy and reduced operating costs.

A bus incorporating a natural gas engine with an electric drive train and energy storage has the potential to offer large reductions in emissions and fuel consumption for urban transit buses. NASA Lewis in cooperation with government and industry

NASA TM-107540 in Ohio is developing a transit bus using these technologies.

\section{DISCUSSION}

\section{A. Hybrid Electric Vehicle Concept}

In recent years an evolution in power electronics technology has offered the possibility of revolutionary drive trains for passenger vehicles. Electric motors using efficient solid state power devices offer infinitely variable power and speed control. Several of the motors currently being offered by industry have very high power densities and can be controlled to also act as generators. When coupled with onboard energy storage systems such as chemical batteries, capacitors, or flywheels, this new drive train offers several advantages including:

- Elimination of multiple-gear transmissions

- Elimination of fluid coupling losses

- Near constant speed and load to the engine

- Recovery of energy during braking

- Reduced drive train and brake maintenance

Electrical power trains with energy storage uncouple the short-term power requirements of the vehicle from the load seen by the engine. An engine in such a power train can operate at its highest efficiency design point. In addition, the size of the engine can be reduced significantly in some vehicles and drive cycles to the long-term average value of power. Energy storage provides the short term power supplement needed during acceleration and for going up a grade. This reduced engine size, higher efficiency, and constant speed yields significantly improved emissions, fuel economy, and life for the engine.

\section{B. Project Objectives and Team Approach}

The project objectives are to design, build, and demonstrate a hybrid electric transit bus. A cooperative of several organizations including 
industrial companies, federal and local government agencies, and academia are supporting this as a joint venture. The members of the group are providing components, systems, test facilities, and operational support to the project.

The governmental bodies believe that this effort will make a significant contribution to addressing the national and state interests to reduce emissions in urban areas. They also believe it will reduce fossil fuel consumption and operating costs for the mass transit systems. In addition, this is an excellent opportunity to capitalize on, and transfer technology from the aerospace and military industries to a commercial venture.

The industry partners objective is to develop advanced transit buses and drive train products that can address the needs of the transit bus market with respect to emissions and operating cost. The vehicle must be competitive, in terms of initial capital cost as well as operating costs, with current low emission urban transit buses.

Key factors in defining the overall project approach have been the selection of the industry team and the decision to concentrate on the power plant and drive train system. Market and technology leaders in the transit bus, engine, and electric motor industries were chosen to join this cooperative venture to insure that a viable commercial production and marketing capability would be available at the end of the project. Companies who could act in a vertical OEM/supplier market were sought rather than competing OEMs or component suppliers to facilitate future manufacturing agreements. In addition, cost sharing was required for industry members to act as full partners. A description of the key partners and their roles follow.

In addition to initiating the project, the NASA Lewis Research Center provides overall project coordination and technical expertise in system modeling, as well as key component selection. In addition, NASA is responsible for developing the overall vehicle power control system including energy storage charge/discharge circuitry and control algorithm development. In general, off-theshelf components have been integrated into the power management system. Key technology in this area developed by NASA will be disseminated for use and manufacturing by industry.

The Greater Cleveland Regional Transit Authority (GCRTA) is a large urban transit agency operating

NASA TM-107540 over 700 buses in the city of Cleveland and is a good representative of the potential customer. It is located near the other partners and has aggressively introduced new low emissions technology. In addition it has developed the infrastructure to support alternative fuels, especially, natural gas. The GCRTA provided the initial vehicle and is supporting the vehicle testing.

Bowling Green State University (BGSU), College of Technology, is a leader in the development of electric vehicle drive trains. BGSU and the Lincoln Electric Motor Division developed the electric traction and auxiliary motors. BGSU also engineered and assembled the major drive train components onto the rear engine cradle of the bus.

Howard University (Washington, DC) is responsible for developing advanced energy management algorithms using neural network technologies. This may offer more efficient operation of the buses by adjusting the state of the energy system based on recognition of variable route conditions. These algorithms will be incorporated into the vehicle controller in the future.

Flxible has historically been the dominant producer of 40-ft transit buses. This duty class of urban transit buses is the mainstay of the industry. Fixible became a market leader by producing an advanced semimonocoque aluminum bodied vehicle at the lowest cost. Though the 40-ft Flxible bus is currently out of production, Flxible is supporting this project with vehicle engineering and integration and is pursuing the future hybrid electric market.

Teledyne Ryan Aeronautical (TRA) is one of the largest producers of small gas turbines. In addition, TRA's unique low cost manufacturing capability, almost entirely based on casting techniques, was seen as critical to insure the final system would be cost competitive. This technology is a result of competing in the "disposable" cruise missile engine market where large military contracts are extremely cost competitive. Although the initial vehicie uses a reciprocating engine, future plans for the project include the use of a Teledyne gas turbine generator unit. The gas turbine offers many advantages over those competing reciprocating engines including the following:

- Low emissions

- Multiple fuels capability

- Elimination of the liquid cooling system

- Smooth and quiet operation

- Compact size and low weight

- Low parts count and high reliability 
The emphasis of the program is on the power train because these systems offer the most effective means to improve emissions and fuel consumption. It is expected that power train products will result from this effort which can be used by other U.S. bus manufacturers also. Finally, it is the intent that where possible, the components developed be applicable for use in automobiles. This will result in lower cost to the bus industry through the greater mass production of the automobile industry

\section{Vehicle and Power Train Configuration}

The hybrid electric transit bus is configured as a series hybrid as shown in Figure 1. In a series hybrid, all power developed by the power plant is converted to electrical power. The combination of electrical power from the engine-generator and the energy storage system power the single centrally located variable speed electric motor that is attached to the rear differential/axle. All power requirements of the bus are obtained from the energy storage system and the engine-generator including lighting, heating, air conditioning, pneumatics, and other vehicle subsystems.

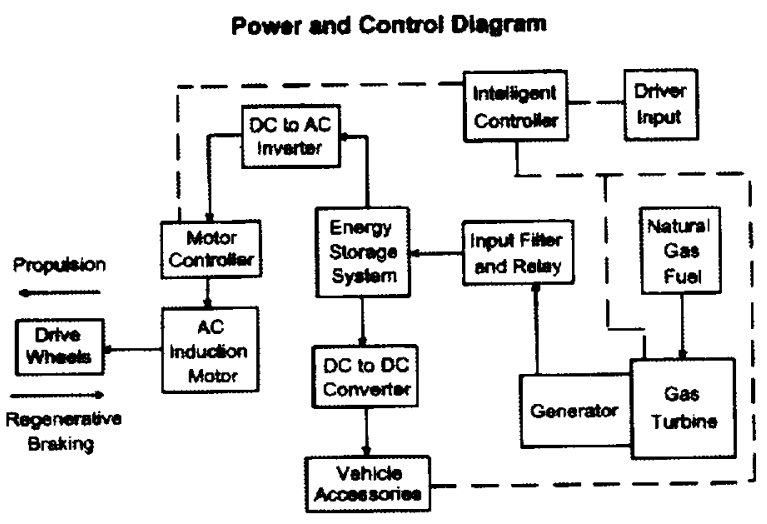

Figure 1. Series Hybrid Schematic

The energy storage system uses a set of thirty super capacitors to store electrical energy. The total capacitor bank is capable of storing $1600 \mathrm{~kJ}$ (about 20 Farads at $400 \mathrm{~V}$ ). The capacitor bank weighs about 2100 lbs. This state-of-the-art technology not only has much longer life than conventional batteries, but it also provides exceptional capability to recover energy that would otherwise be lost during braking. This is the largest vehicle ever built using super capacitor energy storage.

NASA TM-107540
The electric traction motor is a four-quadrant vector controlled $A C$ induction motor. Induction motors offer high reliability and vector controllers allow for independent and efficient control of torque over a wide speed range. With its lightweight alloy frame and the BGSU designed oil cooling, the Lincoln Electric motor achieves $200 \mathrm{HP}$ while weighing only 350 lbs. A separate auxiliary motor drives the major subsystem loads such as air conditioning, and air and hydraulic pumps.

The power management and data system consists of a microprocessor-based Programmable Logic Controller (PLC) controller, a portable computer for data acquisition, and a communication bus. The PLC controller provides sequencing for system/subsystem startup and shutdown as well as control of the state of discharge of the energy storage system. The state of the energy storage must be optimized to allow for full recovery of energy during braking while also considering system cycle life. Finally, the vehicle must respond to operator accellerator and brake controls as similarily as possible to the response of a conventional vehicle

\section{Systems Performance and Emissions}

System model development and analyses were key to selecting the design configuration and the power system components. A computer program, HEVA, (an acronym for Hybrid Electric Vehicle Analysis) was developed at NASA Lewis and was the primary system performance analysis modeling tool. HEVA is written in the $C$ computer language and is presently implemented on a personal computer. HEVA's present capability includes power flow analysis, energy storage state-of-charge, and fuel economy estimates for a hybrid vehicle operating over a defined transient driving cycle. Power loss models for aerodynamic drag, rolling resistance, road inclination, vehicle acceleration, and component inefficiencies are included as well as a power recovery model for regenerative braking.

Initial system studies have used the drive cycle velocity profile defined in the Department of Transporation's Transit Bus "White Book" specifications of reference 1 . This drive cycle consists of three phases to be repeated in sequence: (1) a central business district phase of 2 miles with 7 stops per mile and and top speed of 20 $\mathrm{mph},(2)$ an arterial route phase of 2 miles with 2 stops per mile and a top speed of $40 \mathrm{mph}$, and (3) a 
commuter phase of 4 miles with 1 stop and a maximum speed of $55 \mathrm{mph}$.

A study was made using HEVA to first determine how the energy is used over this drive cycle. As shown in Figure 2, the largest $(48 \%)$ use of the energy is in acceleration of the bus, with smaller and approximately equal energy used for each of the following: (1) aerodynamic drag, $18 \%$; (2) tire rolling resistance, $17 \%$; and (3) drive train losses, $17 \%$.

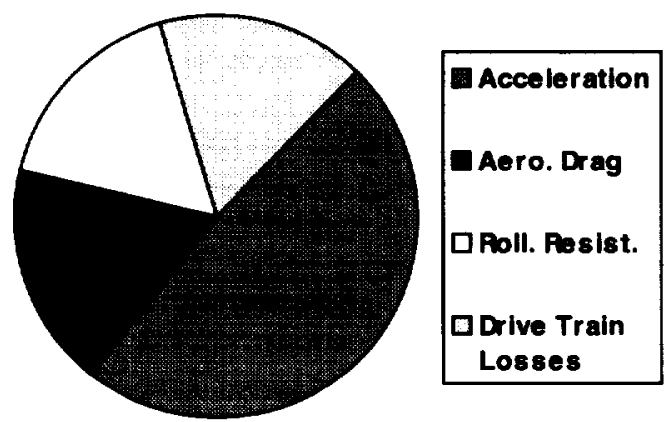

Figure 2. Vehicle Energy Usage

An important conclusion to be drawn is that there is a great potential to recover energy that was used for acceleration for these heavy transit buses in urban drive cycles. Drive train losses are also significant and result primarily from slippage losses in the automatic transmissions. This occurs primarily during acceleration (high torque) below the lockup speed of about $30 \mathrm{mph}$. Since the transit bus spends much of its time under these conditions, there is significant potential for improving efficiency during acceleration. The remaining energy losses in tire rolling resistance and aerodynamic drag are important but will not be addressed as part of this effort.

The peak power requirement during the drive cycle is important with respect to sizing of the traction motor. For this study, the peak power is approximately $250 \mathrm{hp}$ and occurs during acceleration in the commuter phase of the drive cycle. The current Otto and Diesel bus engines are sized for this value. In the hybrid, the electric traction motor must also be sized relative to this value to provide the required acceleration. Electric motors are generally thermally limited, however, and the 200-hp motor is expected to be adequate.

The average power requirement over the drive cycle is important with respect to sizing the engine

NASA TM-107540 generator. Results of this study yielded an average power requirement of about $47 \mathrm{hp}$ to meet the drive cycle requirements. However, additional power requirements result from subsystem loads. Department of Transportation studies measured subsystem power requirements for a Fixible 40-ft transit bus. This data shows the average power required for the air conditioning, air compressor power steering pump, and the alternator total $26 \mathrm{hp}$. Thus the total average power for the vehicle is 73 hp or about $54 \mathrm{~kW}$ for the White Book design cycle. Additional analyses based on drive cycle data taken by NASA on the Cleveland RTA Inner City Loop yields lower power requirements than the White Book cycle presented here and well within the power capability of the engine generator unit.

The expected fuel economy of the hybrid bus compared to today's buses is shown in Figure 3, as predicted by HEVA. Two drive cycles were analyzed. The first represents city driving using measured velocity versus time data as input to HEVA from operation on the Cleveland RTA inner city loop. The Cleveland RTA Inner City Loop is one of the most severe for fuel consumption because approximately half of the time the engine is at idle and operating at its lowest efficiency. The other driving cycle is based on data measured on an arterial-driving route. This analysis provides the bases for the goal of doubling the fuel economy for the hybrid compared to today's buses.

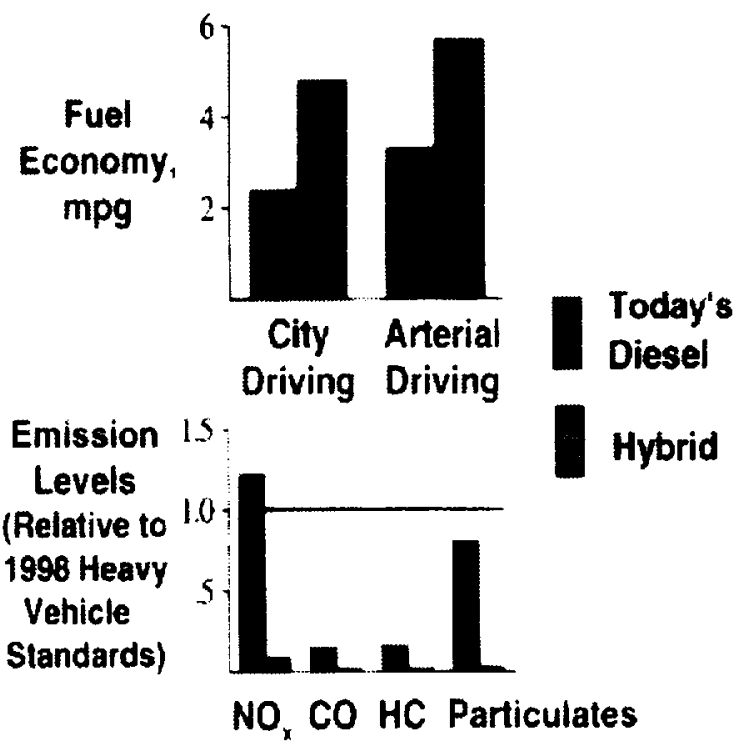

Figure 3. Predicted Fuel Economy and Emissions 
The gas turbine being developed for testing in 1998 offers a significant advantage with respect to exhaust emissions over reciprocating engines. Its continuous combustion process and high aiflow rates results in low hydrocarbon $(\mathrm{HC})$, carbon monoxide ( $\mathrm{CO}$ ), and particulate production even without exhaust catalytic converters. Nitric oxides (NO) production, though relatively low for gas turbines, is dependent on the resident time at high temperature and the efficiency of the fuel injectors in prevaporizing liquid jet fuel. The Teledyne Model 204 gas turbine to be used here has two characterics that will contribute to low NOx production. First, it operates at a relatively low turbine inlet temperature of about 1800F. Second, because the intended fuel is natural gas, it exits the fuel injector as gas, yielding better air and fuel mixing and thus offering the benefits of prevaporized combustors.

The expected emissions for the turboelectric bus, normalized with respect to the 1998 EPAVARB standards for transit buses, are shown in Figure 3. While conventional Diesel engines are having difficulty achieving the 1998 standards, the turboelectric hybrid is expected to reduce emissions by about a factor of 10 .

\section{E. Project Status and Future Plans}

Assembly of the prototype vehicle was completed in July 1997 . For initial testing, a reciprocating engine powered electric generator is being used until the turbogenerator is available. This power plant is essentially the same power output as the turbogenerator that will be used in 1998.

Results from the early vehicle testing were not available at the time of this writing, but should be by the time this paper is presented. Planned testing includes vehicle acceleration, braking and handling, and reliability. Testing is expected to continue throughout the last quarter of calendar year 1997 at the Transportation Research Center in East Liberty, Ohio.

It is expected that the initial vehicle will then be tested under city driving conditions in Cleveland in the latter part of 1997 and early 1998. Plans for further demonstrations of similar vehicles at other locations are currently being developed.

\section{CONCLUSIONS}

A government and industry cooperative is using advanced power technology in a city transit bus that will offer double the fuel economy, and emissions, one tenth of government standards. A unique aspect of the vehicle's design is its use of "super" capacitors for recovery of energy during braking. Future plans include use of a gas turbine powered generator in early 1998.

\section{ACKNOWLEDGEMENTS}

I would like to acknowledge all the members of the Ohio Hybrid Bus team who have been key to the success of this effort, along with their associated organizations:

- Bowling Green State University

- Fixible Bus

- Greater Cleveland Regional Transit Authority

- Howard University

- Lincoln Electric Motor Division

- NASA Lewis Research Center

- Ohio Department of Development

- Teledyne Ryan Aeronautical

\section{REFERENCES}

1. "Baseline Advanced Design Transit Coach Specifications," Department of Transportation, 1978.

Dr. Viterna is a Program Manager at NASA Lewis with 20 years of engineering experience in terrestrial and space power systems. His specific areas of expertise include: power system performance and reliability; computational fluid mechanics and phase change; propeller and wind turbine aerodynamics; and hybrid electric vehicles. He has authored fourteen NASA technical reports and six computer programs. Dr. Viterna obtained his Bachelor of Science and Doctorate degrees from the University of Michigan. 


\begin{tabular}{|c|c|c|c|}
\hline \multicolumn{3}{|c|}{ REPORT DOCUMENTATION PAGE } & $\begin{array}{l}\text { Form Approved } \\
\text { OMB No. } 0704-0188\end{array}$ \\
\hline \multicolumn{4}{|c|}{ 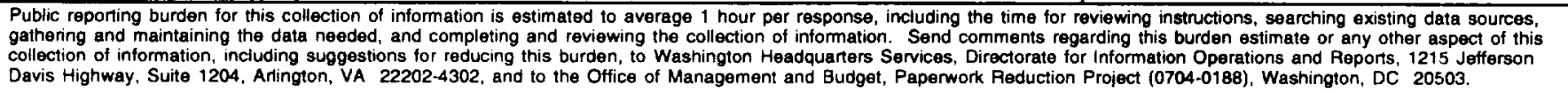 } \\
\hline 1. AGENCY USE ONLY (Leave blank) & $\begin{array}{r}\text { 2. REPORT DATE } \\
\text { August } 1997 \\
\end{array}$ & \multicolumn{2}{|c|}{$\begin{array}{r}\text { 3. REPOAT TYPE AND DATES COVERED } \\
\text { Technical Memorandum }\end{array}$} \\
\hline \multicolumn{3}{|c|}{$\begin{array}{l}\text { 4. TITLE AND SUBTITLE } \\
\text { NASA's Involvement in Technology Development and Transfer: } \\
\text { The Ohio Hybrid Bus Project }\end{array}$} & \multirow{2}{*}{$\begin{array}{l}\text { 5. FUNDING NUMBERS } \\
\text { WU-243-30-07-00 }\end{array}$} \\
\hline \multicolumn{3}{|l|}{$\begin{array}{l}\text { 6. AUTHOR(S) } \\
\text { Larry A. Viterna }\end{array}$} & \\
\hline \multicolumn{3}{|c|}{$\begin{array}{l}\text { 7. PERFORMING ORGANIZATION NAME(S) AND ADDRESS(ES) } \\
\text { National Aeronautics and Space Administration } \\
\text { Lewis Research Center } \\
\text { Cleveland, Ohio } 44135-3191\end{array}$} & $\begin{array}{l}\text { 8. PERFORMING ORGANIZATION } \\
\text { REPORT NUMBER } \\
\text { E-10863 }\end{array}$ \\
\hline \multicolumn{3}{|c|}{$\begin{array}{l}\text { National Aeronautics and Space Administration } \\
\text { Washington, DC 20546-0001 }\end{array}$} & $\begin{array}{l}\text { 10. SPONSORINGMONITORING } \\
\text { AGENCY REPORT NUMBER } \\
\text { NASA TM }-107540\end{array}$ \\
\hline \multicolumn{4}{|c|}{$\begin{array}{l}\text { 11. SUPPLEMENTARY NOTES } \\
\text { Prepared for the Electrical Insulation Conference/Electrical Manufacturing and Coil Winding Expo '97 cosponsored by } \\
\text { IEEE, NEMA, and EMCWA, Chicago, Illinois, September 22-25, 1997. Responsible person, Larry A. Viterna, organiza- } \\
\text { tion code } 6920,(216) 433-5398 \text {. }\end{array}$} \\
\hline \multicolumn{3}{|c|}{$\begin{array}{l}\text { 12a. DISTRIBUTION/AVALABILITY STATEMENT } \\
\text { Unclassified - Unlimited } \\
\text { Subject Category } 85 \\
\text { This publication is available from the NASA Center for AeroSpace Information, (301) 621-0390. }\end{array}$} & 12b. DISTRIBUTION CODE \\
\hline \multicolumn{4}{|c|}{$\begin{array}{l}\text { A government and industry cooperative is using advanced power technology in a city transit bus that will offer double the } \\
\text { fuel economy, and reduce emissions to one tenth of government standards. The heart of the vehicle's power system is a } \\
\text { natural gas fueled generator unit. Power from both the generator and an advanced energy storage system is provided to a } \\
\text { variable speed electric motor attached to the rear drive axle. A unique aspect of the vehicle's design is its use of "super" } \\
\text { capacitors for recovery of energy during braking. This is the largest vehicle ever built using this advanced energy recovery } \\
\text { technology. This paper describes the project goals and approach, results of its system performance modeling, and the } \\
\text { status of the development team's effort. }\end{array}$} \\
\hline \multirow{2}{*}{\multicolumn{2}{|c|}{$\begin{array}{l}\text { 14. SUBJECT TERMS } \\
\text { Hybrid electric vehicles }\end{array}$}} & & \begin{tabular}{|c|} 
15. NUMBER OF PAGES \\
8 \\
\end{tabular} \\
\hline & & & $\begin{array}{r}\text { 16. PRICE CODE } \\
\text { A02 }\end{array}$ \\
\hline $\begin{array}{l}\text { 17. SECURITY CLASSIFICATION } \\
\text { OF REPORT } \\
\text { Unclassified }\end{array}$ & $\begin{array}{l}\text { 18. SECURITY CLASSIFICATION } \\
\text { OF THIS PAGE } \\
\text { Unclassified }\end{array}$ & $\begin{array}{l}\text { 19. SECURITY CLASSIFICATIC } \\
\text { OF ABSTRACT } \\
\text { Unclassified }\end{array}$ & 20. LIMITATION OF ABSTRACT \\
\hline
\end{tabular}

